\title{
Association of prepregnancy body mass index, rate of gestational weight gain with pregnancy outcomes in Chinese urban women
}

Xueyin Wang ${ }^{*}$ (D), Xiaosong Zhang, Min Zhou, Juan Juan and Xu Wang

\begin{abstract}
Background: The prevalence of obesity and excessive gestational weight gain (GWG) has been increasing worldwide. The aims of this study were to evaluate associations of prepregnancy body mass index (BMI) and rate of GWG in the 2nd and 3rd trimesters with pregnancy outcomes in Chinese urban women, and to examine the dose-response relationship between rate of GWG and pregnancy outcomes.

Methods: A retrospective analysis included 8926 women who delivered live singletons at $\geq 28$ weeks of gestation between June 2012 and March 2013 among Chinese urban women. BMI was classified into underweight (BMl $<18.5$ $\left.\mathrm{kg} / \mathrm{m}^{2}\right)$, normal weight $\left(18.5 \mathrm{~kg} / \mathrm{m}^{2} \leq \mathrm{BMl}<24 \mathrm{~kg} / \mathrm{m}^{2}\right)$, overweight $\left(24 \mathrm{~kg} / \mathrm{m}^{2} \leq \mathrm{BMl}<28 \mathrm{~kg} / \mathrm{m}^{2}\right)$ and obese $\left(\mathrm{BMI} \geq 28 \mathrm{~kg} / \mathrm{m}^{2}\right)$ according to the Chinese standard. Rate of GWG in the 2nd and 3rd trimesters was classified as insufficient, adequate and excessive if it was below, within, or above the 2009 IOM guidelines (0.44-0.58 $\mathrm{kg} / \mathrm{w}$ [underweight], $0.35-0.50 \mathrm{~kg} / \mathrm{w}$ [normal], $0.23-0.33 \mathrm{~kg} / \mathrm{w}$ [overweight], and $0.17-0.27 \mathrm{~kg} / \mathrm{w}$ [obese]). Logistic regression models and restricted cubic spline analyses were used to assess the association of prepregnancy $\mathrm{BMI}$ and rate of GWG with cesarean delivery, preterm birth, small-for-gestational age (SGA) and large-forgestational age (LGA).
\end{abstract}

Results: 22.6 and 50.0\% of women had insufficient and excessive rate of GWG, respectively. After adjustment for potential confounders, prepregnancy underweight was associated with increased risk of SGA (OR=1.71, 95\% Cl: 1.402.09), while both overweight and obesity were associated with higher risk of cesarean delivery (overweight: OR [95\% $\mathrm{CI}$ = 1.80 [1.56-2.08]; obese: 2.34 [1.69-3.24]) and LGA (overweight: 1.75 [1.44-2.13]; obese: 2.48 [1.71-3.60]). Both insufficient $(\mathrm{OR}=1.34,95 \% \mathrm{Cl}: 1.08-1.65)$ and excessive rates of $\mathrm{GWG}(\mathrm{OR}=1.44,95 \% \mathrm{Cl}: 1.20-1.73)$ were associated with higher risk of preterm birth. Insufficient rate of GWG was associated with increased odds of SGA (OR $=1.49,95 \%$ Cl: 1.16-1.82), while excessive rate of GWG was associated with higher risk for cesarean delivery $(\mathrm{OR}=1.22,95 \% \mathrm{Cl}$ : 1.10-1.35) and $\mathrm{LGA}(\mathrm{OR}=1.58,95 \% \mathrm{Cl}: 1.33-1.87)$. Additionally, there were significant nonlinear associations between rate of GWG and preterm birth (U-shaped, $P$ for nonlinear $<0.001$ ).

Conclusions: Prepregnancy overweight, obesity and underweight, and insufficient and excessive rate of GWG were associated with increased risk of pregnancy outcomes in Chinese urban women.

Keywords: Gestational weight gain, Body mass index, Pregnancy outcomes, Preterm birth, Cesarean section, Small-forgestational age, Large-for-gestational age, Low birth weight, Macrosomia

\footnotetext{
* Correspondence: xueyin0925@163.com

Department of Obstetrics and Gynecology, Peking University First Hospital,

No. 1 Xi'anmen Street, Xicheng District, Beijing 100034, China
}

(c) The Author(s). 2019 Open Access This article is distributed under the terms of the Creative Commons Attribution 4.0 International License (http://creativecommons.org/licenses/by/4.0/), which permits unrestricted use, distribution, and reproduction in any medium, provided you give appropriate credit to the original author(s) and the source, provide a link to the Creative Commons license, and indicate if changes were made. The Creative Commons Public Domain Dedication waiver (http://creativecommons.org/publicdomain/zero/1.0/) applies to the data made available in this article, unless otherwise stated. 


\section{Background}

Obesity and overweight have become major health concerns in women of childbearing age, and their prevalence has been increasing worldwide. Data from the Pregnancy Risk Assessment Monitoring System (PRAMS) indicated that $45 \%$ of US women who give birth were overweight and obese before pregnancy [1], while overweight and obesity have affected $6 \sim 24 \%$ of Chinese women of reproductive age [2-5]. Prepregnancy overweight or obesity has been associated with a number of poor maternal and neonatal outcomes such as higher risk of cesarean delivery, gestational diabetes mellitus (GDM), pregnancy-induced hypertension (PIH), preterm birth, macrosomia, and low Apgar scores [1, 4, 6]. In addition, maternal obesity may also affect the long-term health of their children, such as increasing the risk of obesity, poor body fat distribution, high blood pressure, adverse lipid profile, and insulin resistance in child and adult offspring [7, 8]. On the other hand, maternal underweight with the prevalence of $11-14 \%$ in Chinese pregnant women has been also associated with suboptimal fetal growth, including low birth weight and small-for-gestational age (SGA) $[2-4,6,9]$.

Gestational weight gain (GWG) is a potentially modifiable risk factor for a series of adverse pregnancy outcomes which could be reduced by nutrition or exercise interventions during pregnancy [10]. Recently, a systematic review and meta-analysis estimated that $47 \%$ of pregnant women had excessive GWG and $23 \%$ had inadequate GWG according to 2009 Institute of Medicine (IOM) recommendations [11]. Excessive GWG has been associated with increased risk of cesarean delivery, hypertensive diseases of pregnancy, postpartum weight retention, macrosomia, and childhood overweight or obesity for the offspring, whereas insufficient GWG may contribute to low birth weight, preterm birth and failure to initiate breast-feeding $[10,12,13]$. In addition, some previous epidemiologic studies using total GWG $(\mathrm{kg})$ as the measurement may introduce bias because of neglecting the inherent correlation between GWG and gestational age at delivery $[14,15]$. Moreover, the rate of GWG is constant and its association with pregnancy time is close to be linear in the 2nd and 3rd trimesters [16], and thus, the rate of GWG in the 2nd and 3rd trimesters would be more preferable for evaluating the association between GWG and pregnancy outcomes. Furthermore, few studies have examined the dose-response relationship between GWG and pregnancy outcomes. To our knowledge, only two studies reported the dose-response relationship between rate of GWG in the 2nd and 3rd trimesters and preterm birth [15, 17].

Therefore, the purpose of the present study was to examine associations of prepregnancy body mass index (BMI) and rate of GWG in the 2nd and 3rd trimesters with pregnancy outcomes in Chinese urban women, and we also assessed the dose-response relationship between rate of GWG and pregnancy outcomes in the whole population and in women stratified by prepregnancy BMI categories.

\section{Methods \\ Study design and participants}

This was a multicenter, retrospective cohort study of postpartum women and their neonates conducted in 14 hospitals in urban areas of China, including 3 centers in Beijing, 2 centers in Guangdong province, 3 centers in Hunan province, 2 centers in Hubei province, 2 centers in Sichuan province and 2 centers in Shanxi province. Women aged $\geq 18$ years with a gestational age of $\geq 28$ weeks and live birth who delivered during 10th-19th of the last month of every quarter from June 2012 to March 2013 were recruited in order to control for seasonal variations. A structured questionnaire was designed to collect information on demographic characteristics, lifestyle behavior, obstetric and medical history of pregnancy, and pregnancy outcomes. During hospitalization for delivery, face-to-face interviews were conducted to collect information on demographic characteristics and lifestyle behavior, and clinical information was obtained retrospectively based on their medical records. Among 9152 participants with full medical history of regularly scheduled antenatal visits and delivery, 226 women with multiple gestation, pre-conception history of severe heart disease or chronic renal disease were excluded. Overall, the current analysis was limited to 8926 deliveries. All participants provided written informed consent, and the study was approved by the institutional review board of Peking University First Hospital.

\section{Classification of prepregnancy BMI and rate of GWG}

The weight (kilograms) and height (meters) of all pregnant women were measured at each antenatal visits in light clothing without shoes. At the enrollment after delivery, weight and height at the first antenatal visit, weight at the last antenatal visit in the first trimester or the first antenatal visit in the 2nd trimester, and weight at the last antenatal visit or the time of delivery were recorded based on the medical records. Prepregnancy BMI was calculated as the weight in kilograms divided by the square of height measured in meters, and classified into four groups according to the Chinese standard [18]: underweight $\left(\right.$ BMI $\left.<18.5 \mathrm{~kg} / \mathrm{m}^{2}\right)$, normal weight $\left(18.5 \mathrm{~kg} / \mathrm{m}^{2} \leq \mathrm{BMI}\right.$ $\left.<24 \mathrm{~kg} / \mathrm{m}^{2}\right)$, overweight $\left(24 \mathrm{~kg} / \mathrm{m}^{2} \leq \mathrm{BMI}<28 \mathrm{~kg} / \mathrm{m}^{2}\right)$ and obese $\left(B M I \geq 28 \mathrm{~kg} / \mathrm{m}^{2}\right)$. The rate of GWG in the 2nd and 3rd trimesters was calculated as: [(final weight measured at the last antenatal visit or the time of delivery - weight measured at the last antenatal visit in the first trimester or the first antenatal visit in 
the 2nd trimester) / (gestational age at delivery - 13 weeks)] [16]. According to the 2009 IOM guidelines, the rate of GWG was classified into insufficient, adequate and excessive if it was below, within, or above the recommendations as follows: $0.44-0.58 \mathrm{~kg} / \mathrm{w}$ (underweight), $0.35-0.50 \mathrm{~kg} / \mathrm{w}$ (normal), $0.23-0.33 \mathrm{~kg} /$ $\mathrm{w}$ (overweight), and $0.17-0.27 \mathrm{~kg} / \mathrm{w}$ (obese) [16].

\section{Definition of pregnancy outcomes}

The main outcomes of this study were cesarean delivery, preterm birth (defined as delivery before 37 weeks gestation [19]), large-for-gestational age (LGA) and SGA. LGA and SGA were indicated by birth weight less than and greater than the 10th and 90th percentile, respectively, for the same gestational age by sex, according to the Chinese neonatal birth weight curve [20].

\section{Assessment of covariates}

Covariates included age, gestational age at delivery, education, drinking during pregnancy, passive smoking, annual household income, number of parity, GDM, and $\mathrm{PIH}$. Age, education, drinking during pregnancy, passive smoking, annual household income and number of parity were assessed by the interviewer-administered questionnaire. Gestational age at delivery was determined from the date of last menstrual period to the date of delivery and expressed in the week after the last menstrual period. If the date was uncertain, ultrasonography was used to determine gestational age. GDM was diagnosed according to the diagnostic criteria amended by China's Ministry of Health [21], which recommend that the diagnosis should be made when any one of the following values is met or exceeded in the 75 oral glucose tolerance test at $24-28$ weeks: $0 \mathrm{~h}, 5.1 \mathrm{mmol} / \mathrm{L} ; 1 \mathrm{~h}, 10.0$ $\mathrm{mmol} / \mathrm{L}$; and $2 \mathrm{~h} 8.5 \mathrm{mmol} / \mathrm{L}$. PIH was defined as systolic blood pressure $\geq 140 \mathrm{mmHg}$ or diastolic blood pressure $\geq$ $90 \mathrm{mmHg}$ after 20 weeks of gestation [22].

\section{Statistical analysis}

Demographics characteristics and pregnancy outcomes were presented as numbers and frequency distributions for categorical variables, or median and interquartile range for continuous variables, and were compared using the chi-square test or Kruskal-Wallis test. Multivariable logistic regression models were conducted to estimate odds ratios (ORs) and their 95\% confidence intervals (CIs) of pregnancy outcomes across categories of prepregnancy BMI or rate of GWG. Models were adjusted for age, gestational age at delivery (except for the outcome of preterm birth), education, drinking during pregnancy, passive smoking, annual household income, number of parity, and study centers. Further models included mutual adjustment of prepregnancy BMI or rate of GWG as appropriate. The normal weight group and adequate GWG rate group were used as the reference groups, respectively. Sensitivity analyses were conducted to additionally adjust for GDM and PIH. Restricted cubic spline (RCS) logistic regression models were used to assess nonlinear effects of GWG rate on adverse pregnancy outcomes by treating the median level of GWG rate as the reference, using 4 knots located at the 5th, 35th, 65th, and 95th percentiles of the distribution of GWG rate. Analyses were carried out using SAS software version 9.2 (SAS Institute, Cary, NC), and the RCS was performed using SAS RCS_Reg macro [23]. All $P$ values are two-sided, and a 0.05 level was used to declare significant differences.

\section{Results}

\section{Participant characteristics}

Among 8926 postpartum women, 22.6, 27.4 and $50.0 \%$ of women had insufficient, adequate and excessive rate of GWG, respectively. More than $70 \%$ of participants who were overweight or obese had excessive rate of GWG (Fig. 1). Distribution of pregnancy outcomes, prepregnancy BMI and rate of GWG by study centers is shown in Additional file 1: Table S1 and Additional file 2: Table S2, respectively. Table 1 shows demographic and clinical characteristics of study participants according to the prepregnancy BMI and rate of GWG categories. The prepregnancy BMI was inversely associated with rate of GWG $(P<$ 0.001). Women with greater prepregnancy BMI were more likely to be multiparous, and have a higher risk of GDM and PIH, and were less likely to have a higher level of annual household income (all $P<0.05$ ). Overweight women were slightly older and obese women were more likely to be exposed to passive smoking than women of normal weight (all $P<0.05$ ). Women with excessive rate of GWG had a higher likelihood of $\mathrm{PIH}$, and women with insufficient rate of GWG were more likely to be multiparous, and to have a lower education level than those with adequate rate of GWG (all $P<0.05$ ).

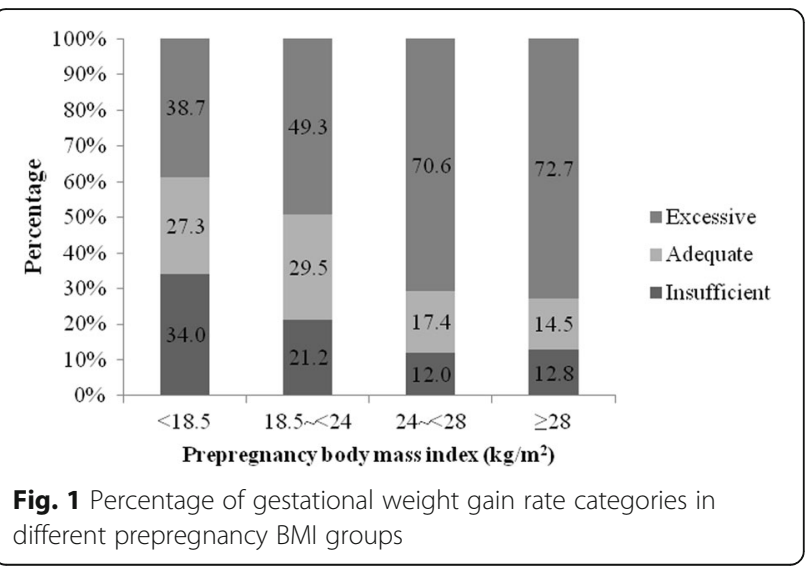


Table 1 Characteristics of participants by prepregnancy BMl and rate of gestational weight gain

\begin{tabular}{|c|c|c|c|c|c|c|c|c|c|}
\hline & \multicolumn{5}{|c|}{ Prepregnancy BMI } & \multicolumn{4}{|c|}{ Gestational weight gain rate } \\
\hline & Underweight & $\begin{array}{l}\text { Normal } \\
\text { weight }\end{array}$ & Overweight & Obese & $P$ value & Insufficient & Adequate & Excessive & $P$ value \\
\hline Participants, n (\%) & $1787(20.0)$ & $6006(67.3)$ & $961(10.8)$ & $172(1.9)$ & & 2018 (22.6) & $2449(27.4)$ & $4459(50.0)$ & \\
\hline $\begin{array}{l}\text { prepregnancy BMl, } \mathrm{kg} / \mathrm{m}^{2} \text {, median } \\
\text { (IQR) }\end{array}$ & $\begin{array}{l}17.6(16.9 \\
18.1)\end{array}$ & $\begin{array}{l}20.6(19.5 \\
21.9)\end{array}$ & $\begin{array}{l}25.1(24.4 \\
26.0)\end{array}$ & $\begin{array}{l}29.4(28.7 \\
31.2)\end{array}$ & $<0.001$ & $\begin{array}{l}20.0(18.3 \\
22.0)\end{array}$ & $\begin{array}{l}20.2(18.8, \\
22.0)\end{array}$ & $\begin{array}{l}20.5(19.1 \\
22.8)\end{array}$ & $<0.001$ \\
\hline $\begin{array}{l}\text { Gestational weight gain rate, } \mathrm{kg} / \mathrm{w} \text {, } \\
\text { median (IQR) }\end{array}$ & $\begin{array}{l}0.42(0.34 \\
0.51)\end{array}$ & $\begin{array}{l}0.40(0.33 \\
0.50)\end{array}$ & $\begin{array}{l}0.35(0.26 \\
0.44)\end{array}$ & $\begin{array}{l}0.29(0.21 \\
0.41)\end{array}$ & $<0.001$ & $\begin{array}{l}0.27(0.19 \\
0.33)\end{array}$ & $\begin{array}{l}0.44(0.38 \\
0.48)\end{array}$ & $\begin{array}{l}0.63(0.56 \\
0.75)\end{array}$ & $<0.001$ \\
\hline Age, years, median (IQR) & $27(25,30)$ & $28(26,31)$ & $29(27,32)$ & $28(26,31)$ & $<0.001$ & $28(25,31)$ & $28(26,31)$ & $28(26,30)$ & 0.005 \\
\hline Gestational age at delivery, week & $39(38,40)$ & $39(38,40)$ & $39(38,40)$ & $39(38,40)$ & 0.183 & $39(38,40)$ & $39(38,40)$ & $39(38,40)$ & $<0.001$ \\
\hline Education & & & & & 0.205 & & & & $<0.001$ \\
\hline High school and below & $1198(67.0)$ & $3914(65.2)$ & $650(67.6)$ & $119(69.2)$ & & $1415(70.1)$ & $1576(64.4)$ & $2890(64.8)$ & \\
\hline College or graduate school & $589(33.0)$ & $2092(34.8)$ & $311(32.4)$ & $53(30.8)$ & & $603(29.9)$ & $873(35.6)$ & 1569 (35.2) & \\
\hline Drinking during pregnancy & & & & & 0.570 & & & & 0.084 \\
\hline Yes & $52(2.9)$ & $160(2.7)$ & $24(2.5)$ & $2(1.2)$ & & $40(2.0)$ & $67(2.7)$ & $131(2.9)$ & \\
\hline No & 1735 (97.1) & $5846(97.3)$ & $937(97.5)$ & $170(98.8)$ & & $1978(98.0)$ & $2382(97.3)$ & $4328(97.1)$ & \\
\hline Smoking during pregnancy & & & & & 0.358 & & & & 0.904 \\
\hline Yes & $5(0.3)$ & $37(0.6)$ & $4(0.4)$ & $1(0.6)$ & & $11(0.6)$ & $14(0.6)$ & $22(0.5)$ & \\
\hline No & $1782(99.7)$ & 5969 (99.4) & 957 (99.6) & $171(99.4)$ & & 2007 (99.4) & $2435(99.4)$ & 4437 (99.5) & \\
\hline Passive smoking & & & & & $<0.001$ & & & & 0.721 \\
\hline Yes & $408(22.8)$ & $1182(19.7)$ & $167(17.4)$ & $44(25.6)$ & & $420(20.8)$ & $489(20.0)$ & $892(20.0)$ & \\
\hline No & $1379(77.2)$ & $4824(80.3)$ & $794(82.6)$ & $128(74.4)$ & & $1598(79.2)$ & $1960(80.0)$ & $3567(80.0)$ & \\
\hline Annual household income, yuan & & & & & 0.009 & & & & 0.752 \\
\hline$<10,000$ & $1426(79.8)$ & 4799 (79.9) & $766(79.7)$ & $147(85.5)$ & & $1609(79.7)$ & $1961(80.1)$ & $3568(80.0)$ & \\
\hline $10,001-20,000$ & 239 (13.4) & $885(14.7)$ & $156(16.2)$ & $20(11.6)$ & & $306(15.2)$ & $358(14.6)$ & $636(14.3)$ & \\
\hline$>20,000$ & $122(6.8)$ & $322(5.4)$ & $39(4.1)$ & $5(2.9)$ & & $103(5.1)$ & $130(5.3)$ & $255(5.7)$ & \\
\hline Number of parity & & & & & $<0.001$ & & & & $<0.001$ \\
\hline Primiparous & $1552(86.9)$ & $4904(81.7)$ & $710(73.9)$ & $125(72.7)$ & & $1559(77.3)$ & $2001(81.7)$ & 3731 (83.7) & \\
\hline Multiparous & $235(13.1)$ & $1102(18.3)$ & $251(26.1)$ & $47(27.3)$ & & $459(22.7)$ & $448(18.3)$ & $728(16.3)$ & \\
\hline Gestational diabetes mellitus & & & & & $<0.001$ & & & & 0.279 \\
\hline Yes & $100(5.6)$ & $539(9.0)$ & $163(17.0)$ & $52(30.2)$ & & $176(8.7)$ & $233(9.5)$ & $445(10.0)$ & \\
\hline No & $1687(94.4)$ & $5467(91.0)$ & $798(83.0)$ & $120(69.8)$ & & $1842(91.3)$ & $2216(90.5)$ & $4014(90.0)$ & \\
\hline $\mathrm{PIH}$ & & & & & $<0.001$ & & & & $<0.001$ \\
\hline Yes & $44(2.5)$ & 237 (3.9) & $82(8.5)$ & $29(16.9)$ & & $52(2.6)$ & $84(3.4)$ & $256(5.7)$ & \\
\hline No & $1743(97.5)$ & $5769(96.1)$ & $879(91.5)$ & $143(83.1)$ & & 1966 (97.4) & 2365 (96.6) & $4203(94.3)$ & \\
\hline
\end{tabular}

Abbreviations: $B M I$ body mass index, GWG gestational weight gain Values are median (IOR) or $\mathrm{n}(\%)$

Additional file 3: Table S3 illustrates the prevalence of adverse pregnancy outcomes by prepregnancy BMI and rate of GWG categories. Prepregnancy BMI and rate of GWG were positively associated with risk of cesarean delivery and LGA (all $P<0.001$ ). Women with underweight and obese had higher prevalence of SGA compared with those of normal weight $(P<0.001)$. Both insufficient and excessive rates of GWG were associated with higher prevalence of preterm birth than those with adequate rate of GWG (all $P<0.01$ ).

\section{Associations of prepregnancy BMI and rate of GWG with pregnancy outcomes}

Table 2 shows associations of adverse pregnancy outcomes with prepregnancy BMI and rate of GWG categories. After adjustment for potential confounders, prepregnancy underweight was associated with higher risk for SGA (OR =1.71, 95\% CI: 1.40-2.09), and both prepregnancy overweight and obesity were associated with higher risk for cesarean delivery (overweight: $\mathrm{OR}=$ 1.80, 95\% CI: $1.56-2.08$; obese: OR $=2.34$, 95\% CI: 1.69 
Table 2 Adjusted ORs (95\% Cls) for pregnancy outcomes by prepregnancy BMI and rate of GWG

\begin{tabular}{|c|c|c|c|c|c|c|c|}
\hline \multirow[t]{2}{*}{ Outcome } & \multicolumn{4}{|c|}{ Prepregnancy BMI ${ }^{\mathrm{a}}$} & \multicolumn{3}{|c|}{ Rate of gestational weight gain ${ }^{b}$} \\
\hline & Underweight & Normal weight & Overweight & Obese & Insufficient & Adequate & Excessive \\
\hline \multicolumn{8}{|l|}{ Cesarean delivery } \\
\hline Case/Non-case & $765 / 1022$ & 2810/3196 & $582 / 379$ & $115 / 58$ & $890 / 1128$ & $1131 / 1318$ & $2250 / 2209$ \\
\hline Model 1 & $0.87(0.78,0.97)$ & Reference & $1.80(1.56,2.08)$ & $2.34(1.69,3.24)$ & $0.91(0.81,1.03)$ & Reference & $1.22(1.10,1.35)$ \\
\hline Model 2 & $0.86(0.77,0.97)$ & Reference & $1.87(1.62,2.16)$ & $2.50(1.80,3.47)$ & $0.93(0.82,1.05)$ & Reference & $1.15(1.04,1.28)$ \\
\hline \multicolumn{8}{|l|}{ Preterm birth ${ }^{c}$} \\
\hline Case/Non-case & $176 / 1611$ & $528 / 5478$ & $92 / 869$ & $17 / 155$ & 203/1815 & $180 / 2269$ & $430 / 4029$ \\
\hline Model 1 & $1.16(0.97,1.40)$ & Reference & $1.12(0.88,1.42)$ & $1.18(0.70,1.98)$ & $1.34(1.08,1.65)$ & Reference & $1.44(1.20,1.73)$ \\
\hline Model 2 & $1.15(0.96,1.39)$ & Reference & $1.19(0.94,1.52)$ & $1.32(0.79,2.23)$ & $1.34(1.08,1.66)$ & Reference & $1.43(1.19,1.72)$ \\
\hline \multicolumn{8}{|l|}{ SGA } \\
\hline Case/Non-case & $161 / 1626$ & $331 / 5675$ & $50 / 911$ & $12 / 160$ & 187/1831 & 158/2291 & $209 / 4250$ \\
\hline Model 1 & $1.71(1.40,2.09)$ & Reference & $0.97(0.71,1.32)$ & $1.42(0.77,2.59)$ & $1.45(1.16,1.82)$ & Reference & $0.75(0.61,0.93)$ \\
\hline Model 2 & $1.74(1.42,2.13)$ & Reference & $0.89(0.65,1.21)$ & $1.19(0.65,2.19)$ & $1.43(1.15,1.79)$ & Reference & $0.77(0.62,0.96)$ \\
\hline \multicolumn{8}{|l|}{ LGA } \\
\hline Case/Non-case & $117 / 1670$ & 608/5398 & $156 / 805$ & $40 / 132$ & 133/1885 & $205 / 2244$ & $583 / 3876$ \\
\hline Model 1 & $0.60(0.49,0.74)$ & Reference & $1.75(1.44,2.13)$ & $2.48(1.71,3.60)$ & $0.78(0.62,0.97)$ & Reference & $1.58(1.33,1.87)$ \\
\hline Model 2 & $0.59(0.48,0.72)$ & Reference & $1.91(1.57,2.33)$ & $2.90(1.99,4.23)$ & $0.79(0.62,0.99)$ & Reference & $1.48(1.24,1.75)$ \\
\hline
\end{tabular}

Abbreviations: $B M I$ body mass index, $C I$ confidence interval, GWG gestational weight gain, OR odds ratio, SGA small-for-gestational age, $L G A$ large-for-gestational age

Values are odds ratios (95\% confidence intervals). Model 1 was adjusted for study centers, age, gestational age at delivery, education, drinking during pregnancy, passive smoking, annual household income, number of parity; Model 2 was additionally adjusted for gestational weight gain (continuous) ${ }^{\mathrm{a}}$ or prepregnancy BMI (continuous) ${ }^{\mathrm{b}}$; Preterm birth was not adjusted for gestational age at delivery ${ }^{\mathrm{c}}$

3.24), and LGA (overweight: $\mathrm{OR}=1.75$, 95\% CI: $1.44-$ 2.13; obese: $\mathrm{OR}=2.48,95 \% \mathrm{CI}: 1.71-3.60)$. Insufficient rate of GWG was associated with increased odds of preterm birth $(\mathrm{OR}=1.34,95 \% \mathrm{CI}: 1.08-1.65)$, and SGA $(\mathrm{OR}=1.45$, 95\% CI: $1.16-1.82)$, while excessive rate of GWG was associated with higher risk for cesarean delivery $(\mathrm{OR}=1.22$, 95\% CI: $1.10-1.35)$, preterm birth $(\mathrm{OR}=$ 1.44, 95\% CI: $1.20-1.73)$, and LGA (OR $=1.58$, 95\% CI: 1.33-1.87). The results remained significant after further mutual adjustment for rate of GWG or prepregnancy BMI.

Sensitivity analyses were conducted to additionally adjust for GDM and PIH, and results were generally similar between models including and not including these two variables (Additional file 4: Table S4). We further examined the relationships between rate of GWG and pregnancy outcomes by prepregnancy BMI categories. Results were generally consistent pertaining to associations of GWG rate with the risk of pregnancy outcomes across different BMI groups, except for cesarean delivery (Additional file 6: Figure S1).

\section{Dose-response relationship of rate of GWG and adverse pregnancy outcomes}

The RCS analysis presented in Additional file 5: Table S5 partly confirmed the results above. Higher levels of GWG rate were associated with higher risk of cesarean delivery and LGA, and associated with lower risk of SGA (all $P$ overall $<0.001$ ). Both lower and higher levels of GWG rate were associated with increased risk of preterm birth compared with the median of GWG rate of $0.50 \mathrm{~kg} / \mathrm{w}(P$ overall $<0.001$, Additional file 5: Table S5 and Fig. 2). Fig. 2 shows the shape of associations between continuous rate of GWG and the risk of preterm birth and LGA based on the RCS logistic regression models. Among all participants, rate of GWG was nonlinearly associated with the risk of preterm birth (U-shaped, $P$ nonlinear $<0.001)$ and LGA $(P$ nonlinear $=$ 0.002 ) after adjustment for potential confounders. Subgroup analysis based on different BMI categories has been shown in Additional file 5: Table S5. Similar results for the shape and the magnitude of associations of GWG rate with the risk of pregnancy outcomes were found between women with normal weight and the whole population.

\section{Discussion}

In this retrospective cohort study of Chinese urban women, 22.6, 27.4 and 50.0\% of women had insufficient, adequate and excessive rate of GWG in the 2nd and 3rd trimesters, respectively, and more than $70 \%$ of women who were overweight or obese had excessive rate of GWG according to the IOM recommendations. We also found that maternal underweight prepregnancy BMI was associated with higher risk of SGA, while overweight or obese pregnancy BMI was associated with increased 

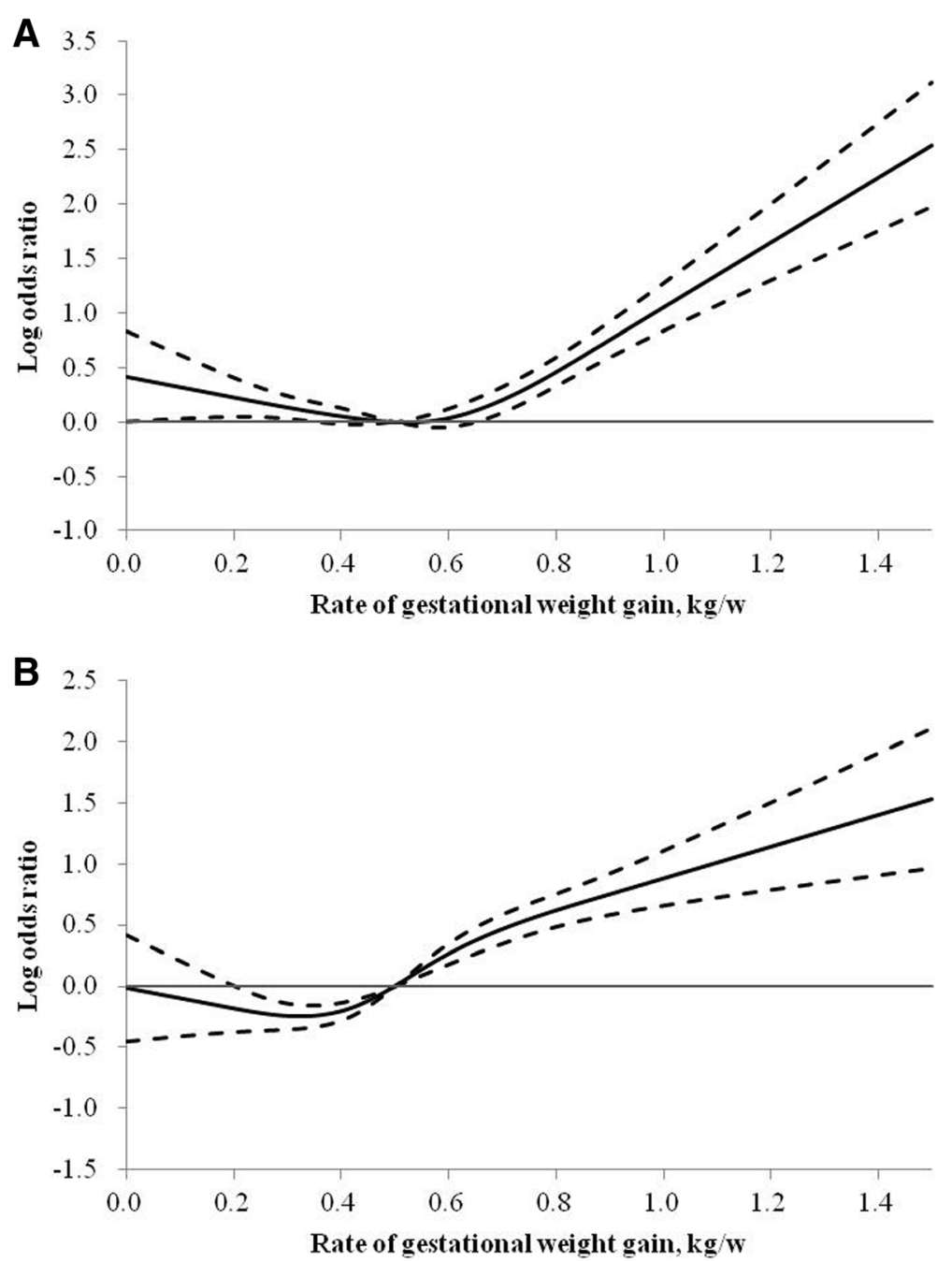

Fig. 2 Log ORs and 95\% Cls for rate of GWG with risk of preterm birth (a) and LGA (b). Abbreviations: BMl, body mass index; Cl, confidence interval; GWG, gestational weight gain; LGA, large-for-gestational age; OR, odds ratio. Adjusted for study centers, age, gestational age at delivery, education, drinking during pregnancy, passive smoking, annual household income, number of parity, and prepregnancy BMl; Preterm birth was not adjusted for gestational age at delivery

odds of cesarean delivery and LGA. After adjusting for potential confounding factors, both insufficient and excessive rates of GWG were associated with higher risk of preterm birth than women with adequate rate of GWG. In addition, insufficient rate of GWG was associated with increased risk of SGA, whereas excessive rate of GWG was associated with higher risk of cesarean delivery and LGA.

One interesting finding of our study is that we observed a U-shaped association of GWG rate with preterm birth by both logistic regression and RCS analysis. Consistent with our findings, a previous study also reported a Ushaped relationship, with both low and high rates of 2 nd and 3rd trimester GWG having a positive association with preterm birth among US pregnancy women [17]. Another study also indicated that the association between rate of
GWG and preterm birth was U-shaped in Peruvian women who were normal-weight or overweight before pregnancy [24]. The potential mechanisms linking insufficient rate of GWG and an elevated risk of preterm birth may involve diminished uteroplacental blood flow, poor expansion of plasma volume, deficiencies in micronutrients, impaired antioxidant activity, infection and inflammation, while excessive rate of GWG may be associated with an increased risk of preterm birth due to induction of a pro-inflammatory state and fluid retention associated with preeclampsia $[24,25]$. Potential mechanisms underlying the association between GWG and preterm birth needed to be further explored in future research.

Another finding of our study is that insufficient rate of GWG was associated with higher risk of SGA. In concordance with our results, the forementioned PRAMS 
cohort also reported that inadequate GWG in underweight and normal prepregnancy BMI groups was associated with increased risk for SGA infants [26]. A largescale retrospective study conducted in Japanese women found that poor GWG was associated with a higher frequency of SGA [6]. Another retrospective cohort study focusing on Taipei women also demonstrated that GWG below the guideline increased the risk of SGA in women with prepregnancy underweight or normal weight [4]. In contrast to a previous study suggesting that GWG below recommendations was associated with a four-fold risk of SGA in US obese women [27], our study demonstrated that insufficient rate of GWG was associated with SGA among women who were prepregnancy underweight or normal weight rather than overweight/obese women. Differences in findings may be partly due to ethnicity disparities. Although factors associated with low GWG and high risk of SGA are largely unknown, several studies inferred that ethnicity, inflammation and preeclampsia might be risk factors for poor fetal growth [28].

The positive associations of prepregnancy BMI and rate of GWG with increased risk of LGA have reported in different populations $[4,6,11,26]$, which is in line with our study. A retrospective cohort study conducted in Taiwanese women also reported that overweight or obese women were at risk for LGA, compared with the women of normal weight, and GWG above the guideline was associated with higher rates of LGA [4]. Another study also revealed that excess GWG was associated with a higher frequency of LGA in Japanese women [6]. Similar to that reported by a recent systematic review and meta-analysis [11], we also found the strongest association between insufficient rate of GWG and lower risk of LGA in underweight women. It might be partly explained by the association of baseline maternal BMI and GWG with changes in the hormonal milieu, including insulin resistance, suggested by animal studies [29].

In addition, we also found that prepregnancy overweight/obesity was associated with an elevated risk of cesarean delivery, which was in accordance with the findings of previous studies [6,30-32]. The association between overweight/obese and increased risk of cesarean delivery might partly due to excess pelvic soft tissue which can lead to a relative obstruction of the birth canal, and decreased rates of cervical dilation and subsequent increased rate of inductions after labor had started $[31,33]$. However, the relationship between rate of GWG and cesarean delivery is still controversial. A prospective cohort study conducted in the Netherlands reported that 1st trimester rate of GWG increased odds of cesarean delivery $(\mathrm{OR}=1.19,95 \%$ CI 1.10-1.29), while rate of 2nd and 3rd trimester GWG was not associated with cesarean delivery [30]. Another retrospective cohort study among Hispanic women indicated that rate of
GWG in the 3rd trimester was associated with a 1.24 odds of cesarean delivery, whereas excessive rate of GWG in the 1st and 2nd trimester was not associated with higher risk of cesarean delivery [31]. In the current study, we observed that rate of GWG in the 2nd and 3rd trimesters was associated with increased risk of cesarean delivery. Prior studies indicated that excessive GWG might contribute to risk of cesarean delivery through an increase in child birth weight, and an elevated rate of preeclampsia independent of prepregnancy BMI $[31,33]$.

The main strengths of this study include a relatively large sample size, using rate of GWG in the 2nd and 3rd trimesters to control for the effect of length of pregnancy on pregnancy outcomes, adjusting for potential confounding factors comprehensively, and utilizing RCS analysis to assess dose-response relationships of GWG rate with adverse pregnancy outcomes. Our study has several limitations. First, our data included only Chinese Han population, and it is unclear whether the results can be extrapolated to women of other ethnic groups. Second, we did not record GWG for different trimesters of pregnancy, so we were unable to examine associations of pregnancy outcomes with rate of GWG in different trimesters. Finally, we did not differentiate spontaneous and induced preterm birth, and did not distinguish between emergency and elective cesarean deliveries.

\section{Conclusion}

In summary, our study indicated that overweight or obese women had higher risk of cesarean delivery and LGA, and underweight women had higher risk of SGA. We observed a U-shaped association between GWG rate in the 2nd and 3rd trimesters and preterm birth. And we found that insufficient rate of GWG was associated with increased risk of SGA, whereas excessive rate of GWG was associated with higher risk of cesarean delivery and LGA. Our findings emphasize the importance of maintaining normal prepregnancy BMI and adequate GWG in preventing adverse pregnancy outcomes by implementing healthy lifestyle strategies before and during pregnancy.

\section{Additional files}

Additional file 1: Table S1. Distribution of pregnancy outcomes by study centers. (DOCX $31 \mathrm{~kb}$ )

Additional file 2: Table S2. Distribution of prepregnancy BMI and rate of gestational weight gain by study centers. (DOCX 20 kb)

Additional file 3: Table S3. Pregnancy outcomes by prepregnancy BMI and rate of gestational weight gain. (DOCX $17 \mathrm{~kb}$ )

Additional file 4: Table S4. Adjusted ORs (95\% Cls) for pregnancy outcomes by prepregnancy BMI and rate of gestational weight gain. (DOCX $16 \mathrm{~kb}$ )

Additional file 5: Table S5. Adjusted ORs (95\% Cls) for pregnancy outcomes and rate of gestational weight gain. (DOCX $19 \mathrm{~kb}$ ) 
Additional file 6: Figure S1. Adjusted ORs for pregnancy outcomes according to prepregnancy BMI and rate of gestational weight gain. Abbreviations: BMI: body mass index; GWG, gestational weight gain; LGA large-for-gestational age; OR: odds ratio; SGA, small-for-gestational age. Values are ORs for cesarean delivery (A), preterm birth (B), SGA (C) and LGA (D). Adjusted for study centers, age, gestational age at delivery, education, drinking during pregnancy, passive smoking, annual household income, and number of parity; Preterm birth was not adjusted for gestational age at delivery ${ }^{*}$. (JPG $52 \mathrm{~kb}$ )

\section{Abbreviations}

BMI: Body mass index; Cl: Confidence interval; GDM: Gestational diabetes mellitus; GWG: Gestational weight gain; IOM: Institute of Medicine; LGA: Large-for-gestational age; OR: Odds ratio; PIH: Pregnancy-induced hypertension; PRAMS: Pregnancy Risk Assessment Monitoring System; RCS: Restricted cubic spline; SGA: Small-for-gestational age

\section{Acknowledgements}

We thank all participants and investigators, and all staff of medical record section in 14 hospitals.

\section{Authors' contributions}

XueyinWang designed this study, analyzed the data, and wrote the manuscript. $X Z$ and $M Z$ contributed to discussion, and edited the manuscript. JJ and XuWang collected and analyzed the data. All authors read and approved the final manuscript.

\section{Funding}

This study was funded by the Scientific Research Seed Fund of Peking University First Hospital Project (2019SF37).

\section{Availability of data and materials}

The datasets analyzed during the current study are available from the corresponding author on reasonable request.

\section{Ethics approval and consent to participate}

The study protocol was approved by the institutional review board of Peking University First Hospital. Informed consent was provided by all participants.

\section{Consent for publication}

Not applicable.

\section{Competing interests}

The authors declare that they have no competing interests.

Received: 24 May 2019 Accepted: 12 August 2019

Published online: 19 August 2019

\section{References}

1. Stang J, Huffman LG. Position of the academy of nutrition and dietetics: obesity, reproduction, and pregnancy outcomes. J Acad Nutr Diet. 2016;116: 677-91.

2. Li C, Liu Y, Zhang W. Joint and independent associations of gestational weight gain and pre-pregnancy body mass index with outcomes of pregnancy in Chinese women: a retrospective cohort study. PLoS One. 2015;10:e0136850

3. Li N, Liu E, Guo J, Pan L, Li B, Wang P, Liu J, Wang Y, Liu G, Baccarelli AA, et al. Maternal prepregnancy body mass index and gestational weight gain on pregnancy outcomes. PLoS One. 2013;8:e82310.

4. Hung T, Hsieh T. Pregestational body mass index, gestational weight gain, and risks for adverse pregnancy outcomes among Taiwanese women: a retrospective cohort study. Taiwan J Obstet Gynecol. 2016;55:575-81.

5. Yang S, Peng A, Wei S, Wu J, Zhao J, Zhang Y, Wang J, Lu Y, Yu Y, Zhang B. Pre-pregnancy body mass index, gestational weight gain, and birth weight: a cohort study in China. PLoS One. 2015;10:e0130101.

6. Enomoto K, Aoki S, Toma R, Fujiwara K, Sakamaki K, Hirahara F. Pregnancy outcomes based on pre-pregnancy body mass index in Japanese women. PLoS One. 2016;11:e0157081.
7. Godfrey KM, Reynolds RM, Prescott SL, Nyirenda M, Jaddoe WW, Eriksson JG, Broekman BF. Influence of maternal obesity on the long-term health of offspring. Lancet Diabetes Endocrinol. 2017;5:53-64.

8. Oostvogels AJ, Stronks K, Roseboom TJ, van der Post JA, van Eijsden M, Vrijkotte TG. Maternal prepregnancy BMI, offspring's early postnatal growth, and metabolic profile at age 5-6 years: the ABCD study. J Clin Endocrinol Metab. 2014;99:3845-54

9. Liu Y, Dai W, Dai X, Li Z. Prepregnancy body mass index and gestational weight gain with the outcome of pregnancy: a 13-year study of 292,568 cases in China. Arch Gynecol Obstet. 2012;286:905-11.

10. Kominiarek MA, Peaceman AM. Gestational weight gain. Am J Obstet Gynecol. 2017;217:642-51.

11. Goldstein RF, Abell SK, Ranasinha S, Misso M, Boyle JA, Black MH, Li N, Hu G, Corrado F, Rode L, et al. Association of Gestational Weight Gain with Maternal and Infant Outcomes: a systematic review and meta-analysis. JAMA. 2017;317:2207-25.

12. Kominiarek MA, Saade G, Mele L, Bailit J, Reddy UM, Wapner RJ, Varner MW, Thorp JM Jr, Caritis SN, Prasad M, et al. Association between gestational weight gain and perinatal outcomes. Obstet Gynecol. 2018;132:875-81.

13. Oken E, Taveras EM, Kleinman KP, Rich-Edwards JW, Gillman MW. Gestational weight gain and child adiposity at age 3 years. Am J Obstet Gynecol. 2007;196:322 e321-8.

14. Hutcheon JA, Bodnar LM, Joseph KS, Abrams B, Simhan HN, Platt RW. The bias in current measures of gestational weight gain. Paediatr Perinat Epidemiol. 2012;26:109-16.

15. Huang A, Ji Z, Zhao W, Hu H, Yang Q, Chen D. Rate of gestational weight gain and preterm birth in relation to prepregnancy body mass indices and trimester: a follow-up study in China. Reprod Health. 2016;13:93.

16. Medicine lo. Weight gain during pregnancy: reexamining the guidelines. Washington (DC): National Academies Press (US); 2009.

17. Sharma AJ, Vesco KK, Bulkley J, Callaghan WM, Bruce FC, Staab J, Hornbrook MC, Berg CJ. Rate of second and third trimester weight gain and preterm delivery among underweight and Normal weight women. Matern Child Health J. 2016:20:2030-6.

18. Wang Y, Mi J, Shan XY, Wang QJ, Ge KY. Is China facing an obesity epidemic and the consequences? The trends in obesity and chronic disease in China. Int J Obes. 2007;31:177-88.

19. Chen CM. Overview of obesity in mainland China. Obes Rev. 2008;9(Suppl 1):14-21.

20. Zhu $L$, Zhang $R$, Zhang $S$, et al. Chinese neonatal birth weight curve for different gestational age. Chin J Pediatr. 2015;53:97-103 (In Chinese).

21. Diagnostic criteria and classification of hyperglycaemia first detected in pregnancy: a World Health Organization guideline. Diabetes Res Clin Pract. 2014;103:341-363.

22. Ishimitsu T. Starting the new review series: pregnancy-induced hypertension. Hypertens Res. 2017:40:3-4.

23. Desquilbet $L$, Mariotti F. Dose-response analyses using restricted cubic spline functions in public health research. Stat Med. 2010;29:1037-57.

24. Carnero AM, Mejia CR, Garcia PJ. Rate of gestational weight gain, prepregnancy body mass index and preterm birth subtypes: a retrospective cohort study from Peru. BJOG. 2012;119:924-35.

25. Goldenberg RL, Culhane JF, lams JD, Romero R. Epidemiology and causes of preterm birth. Lancet. 2008;371:75-84.

26. Shin D, Song WO. Prepregnancy body mass index is an independent risk factor for gestational hypertension, gestational diabetes, preterm labor, and small- and large-for-gestational-age infants. J Matern Fetal Neonatal Med. 2015;28:1679-86.

27. Vesco KK, Sharma AJ, Dietz PM, Rizzo JH, Callaghan WM, England L, Bruce FC, Bachman DJ, Stevens VJ, Hornbrook MC. Newborn size among obese women with weight gain outside the 2009 Institute of Medicine recommendation. Obstet Gynecol. 2011;117:812-8.

28. Catov JM, Abatemarco D, Althouse A, Davis EM, Hubel C. Patterns of gestational weight gain related to fetal growth among women with overweight and obesity. Obesity (Silver Spring). 2015;23:1071-8.

29. Nicholas LM, Rattanatray L, MacLaughlin SM, Ozanne SE, Kleemann DO, Walker SK, Morrison JL, Zhang S, Muhlhausler BS, Martin-Gronert MS, McMillen IC. Differential effects of maternal obesity and weight loss in the periconceptional period on the epigenetic regulation of hepatic insulinsignaling pathways in the offspring. FASEB J. 2013;27:3786-96.

30. Gaillard R, Durmus B, Hofman A, Mackenbach JP, Steegers EA, Jaddoe WW. Risk factors and outcomes of maternal obesity and excessive weight gain during pregnancy. Obesity (Silver Spring). 2013;21:1046-55. 
31. Harvey MW, Braun B, Ertel KA, Pekow PS, Markenson G, Chasan-Taber L. Prepregnancy body mass index, gestational weight gain, and odds of cesarean delivery in Hispanic women. Obesity (Silver Spring). 2018;26: 185-92.

32. Xiong C, Zhou A, Cao Z, Zhang Y, Qiu L, Yao C, Wang Y, Zhang B. Association of pre-pregnancy body mass index, gestational weight gain with cesarean section in term deliveries of China. Sci Rep. 2016;6:37168.

33. Wispelwey BP, Sheiner E. Cesarean delivery in obese women: a

comprehensive review. J Matern Fetal Neonatal Med. 2013;26:547-51.

\section{Publisher's Note}

Springer Nature remains neutral with regard to jurisdictional claims in published maps and institutional affiliations.

Ready to submit your research? Choose BMC and benefit from:

- fast, convenient online submission

- thorough peer review by experienced researchers in your field

- rapid publication on acceptance

- support for research data, including large and complex data types

- gold Open Access which fosters wider collaboration and increased citations

- maximum visibility for your research: over $100 \mathrm{M}$ website views per year

At $\mathrm{BMC}$, research is always in progress.

Learn more biomedcentral.com/submissions 